\title{
Approaching the validation of building energy models: billing vs indoor environmental data
}

\author{
Domenico Palladino ${ }^{1}$, and Iole Nardi ${ }^{1 *}$ \\ ${ }^{1}$ ENEA, DUEE Department, 00123 via Anguillarese 301 Santa Maria di Galeria (Rome), Italy
}

\begin{abstract}
To understand the real building energy consumption, and to identify the best energy improvements (due to energy refurbishment and/or HVAC replacement), the energy audit is recommended, but it generally entails the realization of an energy model of the building itself. The main issue of this approach is the collection of data, needed to verify the reliability of the energy audit results. Currently, to validate buildings energy model retrieved by hourly semi-stationary software, is it possible to refer to: (i) bills related to energy carrier (i.e. natural gas and/or electricity); (ii) monitored indoor parameters. The aim of the paper is to understand which of the two is more suitable for the purpose. In this work, the two options are investigated considering, as case study, a family house located in central Italy, whose envelope thermophysical properties and HVAC systems are known, and whose bills and indoor environmental conditions (air temperature and relative humidity) were archived since December 2019. Results from the two validation methods are very close to each other; particularly, results show that energy audit performed with indoor environmental parameters better fits the real consumption, but it entails more complex validation procedure.
\end{abstract}

\section{Introduction}

Energy audit is a useful tool allowing to identify the real energy consumption of buildings and to find solutions able to improve its energy efficiency [1-2]. The commitment of energy audit was introduced by the European Directive [3] in 2012, solely for the energy-intensive buildings or companies. For the residential and buildings sector, instead, energy audit is mandatory only to access economic incentives. The methodology to be adopted for an energy audit is ruled by [4-5], which provides a validation methodology of model based on energy carrier bills. In Literature, instead, different validation methods are studied and used highlighting the critical issues of each method [6-7]. The most common method is the validation by comparing the monitored indoor environmental conditions with simulated ones, such as in [8-9].

In light of the European Directives, which aim to support building energy audits, it is important to assess which is the best way to verify the accuracy of the audits itself. Indeed, it is possible to refer to: (i) bills related to the energy carrier (i.e. natural gas and electricity); (ii) monitored indoor parameters. However, it can be useful to compare, on a

* Corresponding author: iole.nardi@enea.it 
real building, the results of the two approaches. For the purpose, this paper is presented. An existing and occupied residential building was chosen as case study, and it was investigated by applying both energy audit approaches using a commercial and certificated software. The case study has been investigated since 2019 by acquiring both billing and indoor environmental conditions.

Specifically, two energy audits are carried out:

1) energy audit A: the model simulation from software is validated in compliance with [4] so by using billings;

2) energy audit B: the model simulation from software is validated by using the indoor environmental conditions.

For the second approach, an experimental campaign was carried out, by monitoring and logging indoor environmental conditions (relative humidity and indoor air temperature), whilst outdoor ones were available from a local weather station. Results from the two approaches were compared, and critical outcomes were drawn.

\section{Methodology}

\subsection{Case Study and Experimental acquisition}

Both energy audit A and B required a deep knowledge of the building features (starting from geometric dimension to the thermal characteristics of whole building envelope and HVAC systems). The building selected as case study is located in Central Italy, $30 \mathrm{~km}$ North from Rome. Recently renovated by applying an external thermal coat, new windows installation and HVAC systems replacement, the case study is characterized by high thermal performance of building envelope as shown in Table 1. The building borders below and on the left with two apartments, while on the other sides faces the outside. Both heating and domestic hot water production are satisfied by a condensing boiler of 24.70 $\mathrm{kW}$.

Table 1. Main characteristics of building envelope

\begin{tabular}{|c|c|c|}
\hline Parameters & Values & Unit \\
\hline Net area & 60 & {$\left[\mathrm{~m}^{2}\right]$} \\
\hline Net volume & 174 & {$\left[\mathrm{~m}^{3}\right]$} \\
\hline Uexternal wall & 0.230 & {$\left[\mathrm{~W} / \mathrm{m}^{2} \mathrm{~K}\right]$} \\
\hline$U_{\text {ceiling }}$ & 0.804 & {$\left[\mathrm{~W} / \mathrm{m}^{2} \mathrm{~K}\right]$} \\
\hline Uroof $_{\text {rof }}$ & 0.193 & {$\left[\mathrm{~W} / \mathrm{m}^{2} \mathrm{~K}\right]$} \\
\hline U $_{\text {window }}$ & 2.05 & {$\left[\mathrm{~W} / \mathrm{m}^{2} \mathrm{~K}\right]$} \\
\hline
\end{tabular}

The case study has been investigated since 2019; specifically, all the energy carrier bills were collected since February 2019, while it has been possible to acquire the indoor environmental conditions starting from December 2019 and compatibly with the user's availability. The experimental acquisition and bills collection are still ongoing.

The billing history allowed to retrieve the natural gas consumption of each month, as well as the domestic hot water consumption. Such values are referred to the use of the only person who lived the home, during the days specified in Table 2. 
It is worth noting that water consumption showed in Table 2 was estimated based on the information provided by the occupant during each month. In fact, during all the acquisition period, the user was asked to take note and schedule each day the following information:
1) heating turning on-off;
2) number and time of shower;
3) days of stay;
4) special events (parties, etc).

Based on those information, the heating system power on schedule is proposed in Table 3 . In the house, loggers for the monitoring of air temperature and relative humidity were also installed (red dots in Fig. 1): the monitoring period for each month is specified in Table 2. Indoor environmental conditions are acquired by using seven data logger (Rotronic Instrumentations with an accuracy of $\pm 0.3^{\circ} \mathrm{C}$ and $\pm 0.3 \%$ in $-30 \div+70$ and $0-100 \%$ ranges) able to acquire relative humidity and air temperature. They were placed in different rooms of the building as shown in Fig. 1.

According to information shown in Table 2 and Table 3, monitoring data for whole month are available only for March, April and December, therefore the audit B will be validated considering these three months, whilst the validation of the energy audit A is based on yearround bills [4].

\section{First floor}

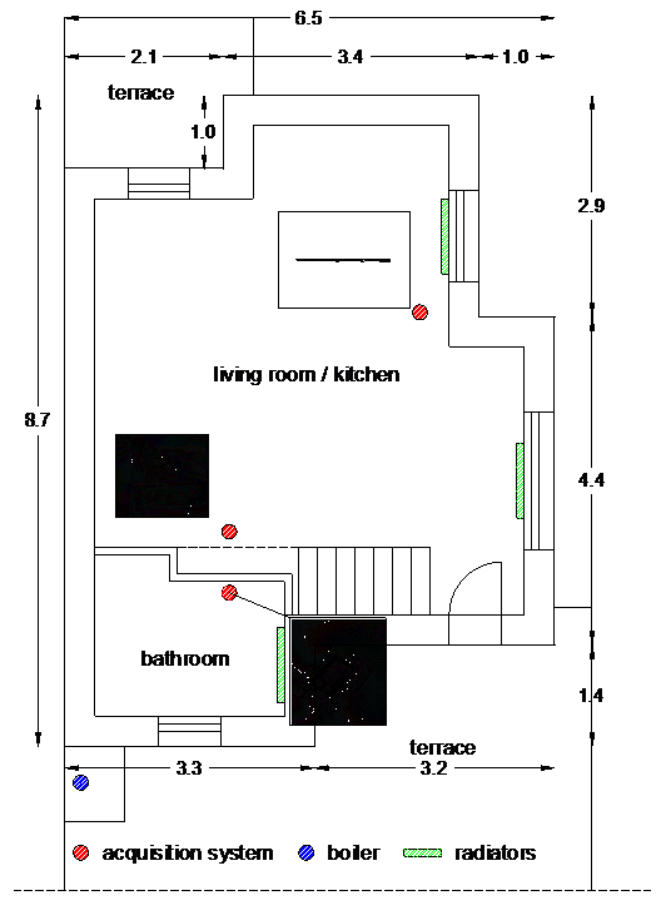

Second floor

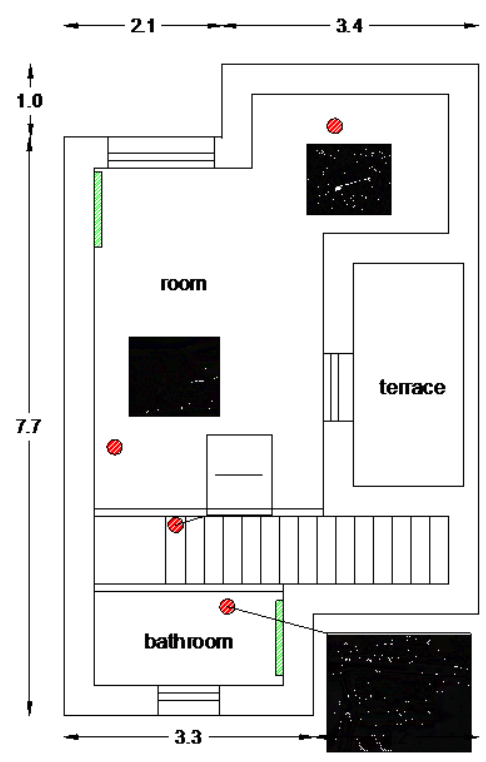

Fig. 1. Building sizes and acquisition systems positioning. 
Table 2. Monitoring period, and consumptions

\begin{tabular}{|c|c|c|c|c|}
\hline Month & $\begin{array}{c}\text { Natural gas } \\
\text { consumption } \\
\text { (from bills) }\left[\mathbf{m}^{3}\right]\end{array}$ & Water $[\mathbf{I}]$ & $\begin{array}{c}\text { Days of } \\
\text { occupancy } \\
{[-]}\end{array}$ & $\begin{array}{c}\text { Monitoring period } \\
\text { [dd/mm/yyyy] }\end{array}$ \\
\hline January & 37 & 106.9 & 20 & $01 / 01 / 2020-07 / 01 / 2020$ \\
\hline February & 26 & 118.4 & 20 & $28 / 02 / 2020-29 / 02 / 2020$ \\
\hline March & 31 & 252.8 & 27 & $01 / 03 / 2020-31 / 03 / 2020$ \\
\hline April & 24 & 290.3 & 30 & $01 / 04 / 2020-30 / 04 / 2020$ \\
\hline May & 8 & 115.5 & 22 & $01 / 05 / 2020-$ in progress \\
\hline June & 6 & 97.2 & 20 & - \\
\hline July & 4 & 68.4 & 15 & - \\
\hline August & 3 & 51.3 & 10 & - \\
\hline September & 3 & 53.0 & 12 & - \\
\hline October & 4 & 64.1 & 15 & - \\
\hline November & 18 & 75.1 & 17 & 98 \\
\hline December & 21 & 51.3 & 12 & $06 / 12 / 2019-31 / 12 / 2019$ \\
\hline Total & 185 & 1344.4 & 220 & \\
\hline
\end{tabular}

Table 3. Heating system turning off schedule

\begin{tabular}{|c|c|c|c|c|c|c|c|}
\hline \multirow{2}{*}{$\begin{array}{l}\text { Day of heating } \\
\text { [dd/mm/yyyy] }\end{array}$} & \multicolumn{3}{|c|}{ Heating system } & \multirow{2}{*}{$\begin{array}{c}\text { Day of } \\
\text { heating } \\
\text { [dd/mm/yyyy] }\end{array}$} & \multicolumn{3}{|c|}{ Heating system } \\
\hline & on & off & hour $[\mathrm{h}]$ & & on & off & hour $[h]$ \\
\hline $28 / 02 / 2020$ & 9:00 & $13: 00$ & 4 & $22 / 04 / 2020$ & $22: 00$ & $0: 00$ & 2 \\
\hline 03/03/2020 & $18: 00$ & $0: 00$ & 6 & $23 / 04 / 2020$ & $22: 00$ & $0: 00$ & 2 \\
\hline $26 / 03 / 2020$ & $18: 00$ & $21: 00$ & 3 & $24 / 04 / 2020$ & $21: 00$ & $0: 00$ & 3 \\
\hline 28/03/2020 & $18: 00$ & 0:00 & 6 & $25 / 04 / 2020$ & $22: 00$ & 0:00 & 2 \\
\hline $30 / 03 / 2020$ & $18: 00$ & $20: 00$ & 2 & $26 / 04 / 2020$ & $18: 00$ & $20: 00$ & 2 \\
\hline $09 / 04 / 2020$ & $18: 00$ & $23: 00$ & 5 & $15 / 12 / 2019$ & $18: 00$ & $20: 00$ & 2 \\
\hline $10 / 04 / 2020$ & $18: 00$ & $23: 00$ & 5 & $18 / 12 / 2019$ & $18: 00$ & $0: 00$ & 6 \\
\hline
\end{tabular}

A 3D simulation model (Fig. 2) is implemented with certified software able to carry out both kind of audit; specifically, the adopted software implemented the dynamic hour calculation provided by UNI EN ISO 52016 [10] 


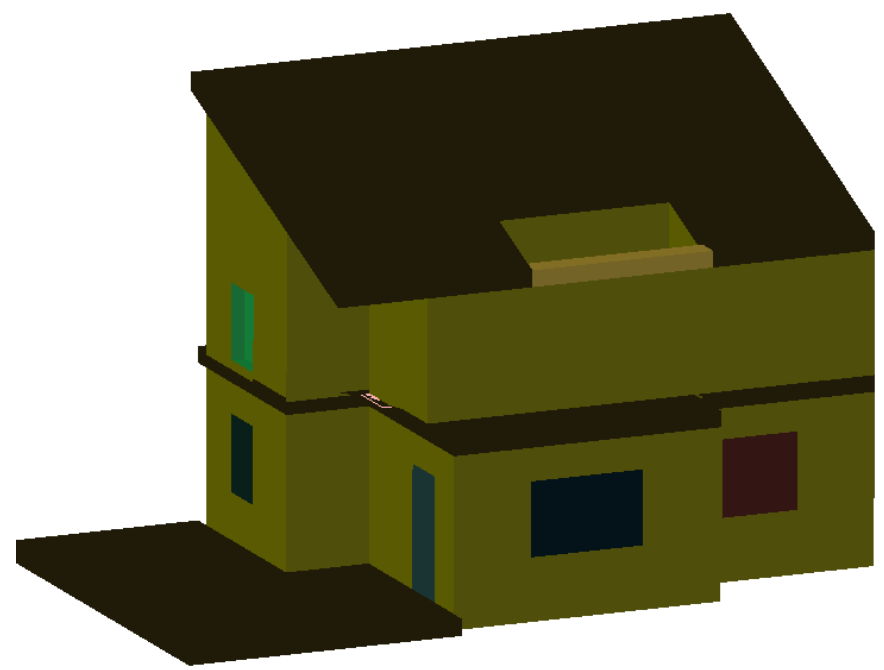

Fig. 2. 3D simulation model

\section{Results}

Firstly, the energy audit A according to [4] was carried out, and then the energy audit B. The thermophysical characteristics of the case study have been implemented in the 3D simulation model, including the internal contributions based on the user's information. Energy simulations are carried out by using the real power on the heating period and the real domestic hot water consumption. For the purpose of the paper, the validation criteria will take into account only the heating period.

\subsection{Energy Audit A - billing}

The validation criterion of energy audit A is based on the comparison between simulated and billed natural gas consumption for the heating purpose $(\mathrm{H})$. Results are shown in Table 4 where natural gas consumption for each service is shown. Specifically, according to information provided by the user regarding the number of meals, cocking time, number of shower, the energy carrier consumption is split in three contributions: cooker $(\mathrm{C})$, domestic hot water production $(\mathrm{W})$ and heating $(\mathrm{H})$, which are assumed as reference values for both the energy audits.

As shown in Table 4, simulated consumption is very close to the billed (relative error of about $-1 \%$, absolute error of about $3 \mathrm{~m}^{3}$ ). The higher differences are found for January, February and November which are three months with user occasional presence within the building and for which few information about power on profile are available. On the other hand, for the months where all information needed are available (March, April and December) a lower absolute and relative error are found. For that, audit A can be considered checked and validated. 
Table 4. Model Validation - Energy Audit A: natural gas consumption comparison

\begin{tabular}{|l|c|c|c|c|c|c|c|c|}
\hline \multirow{2}{*}{ Month } & \multicolumn{6}{|c|}{ Natural gas consumption } & \multicolumn{2}{c|}{ Error } \\
\cline { 2 - 8 } & \multicolumn{3}{|c|}{$\begin{array}{c}\text { Energy carrier bills } \\
{\left[\mathbf{m}^{3}\right]}\end{array}$} & \multicolumn{2}{c|}{$\begin{array}{c}\text { Energy Audit A } \\
{\left[\mathbf{m}^{3}\right]}\end{array}$} & \multirow{2}{*}{$\begin{array}{c}\text { Absolute } \\
{\left[\mathbf{m}^{3}\right]}\end{array}$} & $\begin{array}{c}\text { Relative } \\
{[\%]}\end{array}$ \\
\cline { 2 - 9 } Jotal & $\mathbf{C}$ & $\mathbf{W}$ & $\mathbf{H}$ & $\mathbf{W}$ & $\mathbf{H}$ & 6.1 & $20.6 \%$ \\
\hline February & 26 & 1.5 & 5.8 & 18.7 & 5.8 & 22.6 & -3.9 & $-20.9 \%$ \\
\hline March & 31 & 2.3 & 6.3 & 22.5 & 6.3 & 19.7 & 2.8 & $12.5 \%$ \\
\hline April & 24 & 2.9 & 7.0 & 14.1 & 7.0 & 14.7 & -0.6 & $-4.4 \%$ \\
\hline May & 8 & 1.7 & 6.3 & 0.0 & 6.3 & 0.0 & - & - \\
\hline June & 6 & 1.3 & 4.7 & 0.0 & 4.7 & 0.0 & - & - \\
\hline July & 4 & 0.3 & 3.7 & 0.0 & 3.7 & 0.0 & - & - \\
\hline August & 3 & 0.2 & 2.8 & 0.0 & 2.8 & 0.0 & - & - \\
\hline September & 3 & 0.2 & 2.8 & 0.0 & 2.8 & 0.0 & - & - \\
\hline October & 4 & 0.5 & 3.5 & 0.0 & 3.5 & 0.0 & - & - \\
\hline November & 18 & 0.8 & 3.9 & 13.2 & 3.9 & 14.7 & -1.5 & $-11.4 \%$ \\
\hline December & 21 & 0.6 & 2.8 & 17.6 & 2.8 & 17.9 & -0.3 & $-1.5 \%$ \\
\hline Total & 185 & 13.8 & 55.4 & 115.8 & 55.4 & 113.2 & 2.6 & $-0.8 \%$ \\
\hline
\end{tabular}

\subsection{Energy Audit B - monitoring}

The validation criterion of energy audit $\mathbf{B}$ is based on the comparison between simulated and monitored indoor air temperature. Starting from the indoor air temperature, the energy carrier consumption is calculated. Results from air temperature comparison are shown in Table 5, specifically the mean values for each hour (averaged on the heating days are reported. As shown, the mean simulated indoor air temperature is always very close to the monitored one with an absolute error of about $-0.1^{\circ} \mathrm{C}$. However, the standard deviation simulated by the software is slightly lower the real one.

The air temperature comparison is also shown in Fig. 3, where the simulated temperature trend is shown and compared with the monitored one for three months (March, April, and December) showing a very good agreement. In two cases (one week of March and at the end of December) a higher discrepancy (about $2{ }^{\circ} \mathrm{C}$ ) is found. Except for this limited time period, the difference between simulated air temperature and real one is mainly lower than $0.5{ }^{\circ} \mathrm{C}$ (more than $60 \%$ of cases) and lower than $1{ }^{\circ} \mathrm{C}$ (more than $85 \%$ of cases). According to Fig. 3 and Table 5, the simulation model was considered validated.

Once the model was validated, the natural gas consumption is calculated and compared with the billing: results are shown in Table 6. Also in this case, the simulated consumption is very close to the real total one (relative error of about $-2 \%$, absolute error of about $-2 \mathrm{~m}^{3}$ ). Once again, the higher differences are found for January, February and November which are three months with user occasional presence within the building and for which a few information about power on profile are available. On the other hand, for the months where all information needed are available (March, April and December) a lower absolute and relative error are found. 
Table 5 Model Validation - Energy Audit B (during HVAC turning on)

\begin{tabular}{|c|c|c|c|c|c|}
\hline \multirow{2}{*}{ hour } & \multicolumn{2}{|c|}{$\begin{array}{c}\text { Monitored Temperature } \\
{\left[{ }^{\circ} \mathrm{C}\right]} \\
\end{array}$} & \multicolumn{2}{|c|}{$\begin{array}{c}\text { Simulated Temperature } \\
{\left[{ }^{\circ} \mathrm{C}\right]}\end{array}$} & \multirow{2}{*}{$\begin{array}{c}\text { Mean } \\
\text { Absolute } \\
\text { Error }\left[{ }^{\circ} \mathrm{C}\right]\end{array}$} \\
\hline & $\begin{array}{l}\text { Mean } \\
\text { Value }\end{array}$ & $\begin{array}{l}\text { Standard } \\
\text { Deviation }\end{array}$ & $\begin{array}{l}\text { Mean } \\
\text { Value }\end{array}$ & $\begin{array}{l}\text { Standard } \\
\text { Deviation }\end{array}$ & \\
\hline $\mathbf{0}$ & 16.9 & 2.3 & 16.8 & 1.9 & -0.1 \\
\hline 1 & 16.9 & 2.3 & 16.7 & 1.9 & -0.1 \\
\hline 2 & 16.8 & 2.2 & 16.7 & 1.9 & -0.1 \\
\hline 3 & 16.7 & 2.2 & 16.6 & 1.9 & -0.1 \\
\hline 4 & 16.7 & 2.2 & 16.6 & 1.9 & -0.1 \\
\hline 5 & 16.6 & 2.2 & 16.6 & 1.9 & -0.1 \\
\hline 6 & 16.5 & 2.2 & 16.5 & 1.9 & -0.1 \\
\hline 7 & 16.5 & 2.2 & 16.5 & 2.0 & -0.1 \\
\hline 8 & 16.5 & 2.3 & 16.6 & 2.0 & 0.1 \\
\hline 9 & 16.5 & 2.3 & 16.6 & 2.1 & 0.1 \\
\hline 10 & 16.5 & 2.3 & 16.6 & 2.0 & 0.1 \\
\hline 11 & 16.6 & 2.4 & 16.7 & 2.0 & 0.0 \\
\hline 12 & 16.5 & 2.4 & 16.7 & 2.0 & 0.0 \\
\hline 13 & 16.5 & 2.2 & 16.7 & 2.0 & 0.1 \\
\hline 14 & 16.4 & 2.2 & 16.8 & 2.0 & 0.1 \\
\hline 15 & 16.5 & 2.2 & 16.8 & 1.9 & 0.0 \\
\hline 16 & 16.5 & 2.2 & 16.8 & 2.0 & 0.0 \\
\hline 17 & 16.6 & 2.3 & 16.8 & 2.0 & 0.0 \\
\hline 18 & 16.6 & 2.3 & 16.8 & 2.0 & 0.0 \\
\hline 19 & 16.6 & 2.4 & 16.7 & 1.9 & 0.0 \\
\hline 20 & 16.7 & 2.4 & 16.7 & 1.9 & 0.0 \\
\hline 21 & 16.8 & 2.4 & 16.8 & 2.0 & 0.0 \\
\hline 22 & 16.9 & 2.4 & 16.8 & 2.0 & 0.0 \\
\hline 23 & 16.9 & 2.5 & 16.7 & 2.0 & -0.1 \\
\hline Total & 16.6 & 2.3 & 16.7 & 2.0 & 0.0 \\
\hline
\end{tabular}




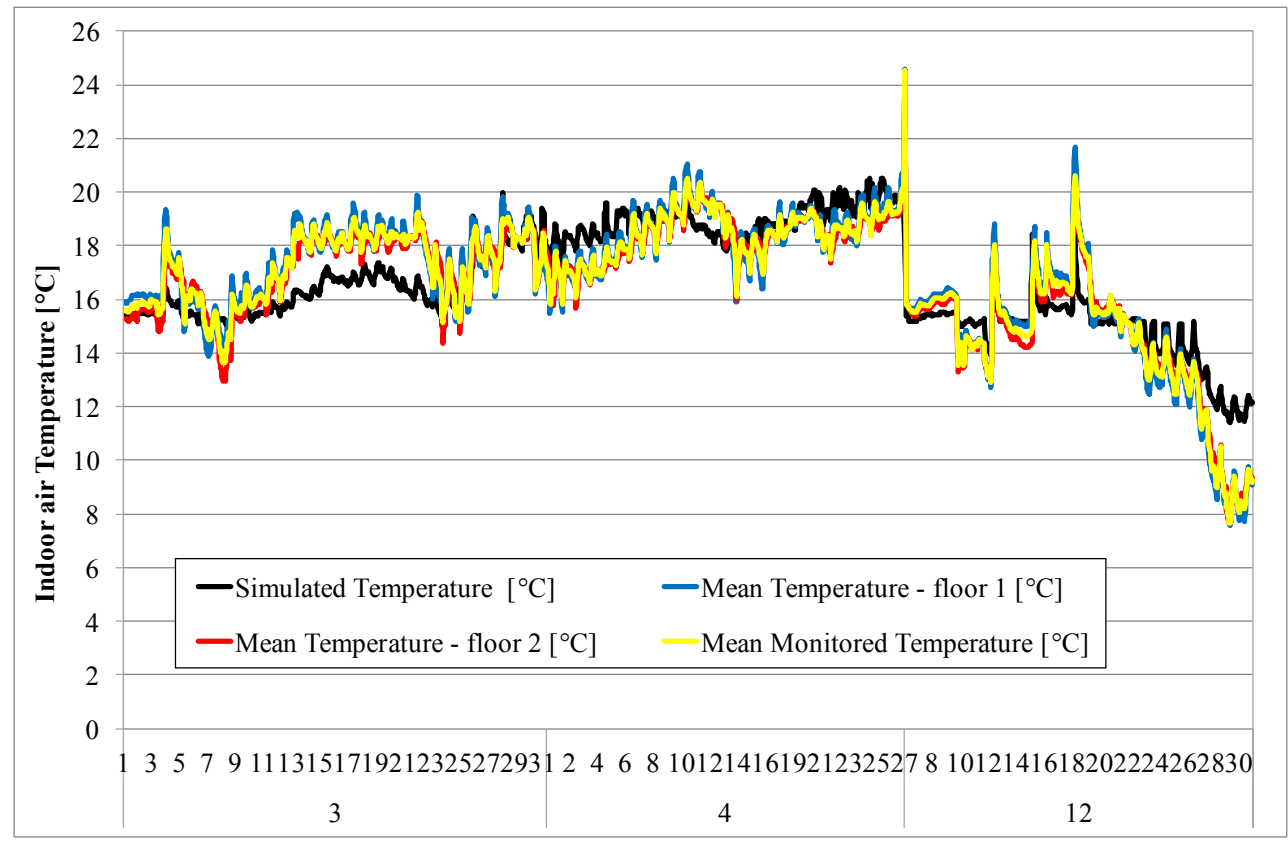

Fig. 3. Model Validation - Energy Audit B: indoor air temperature comparison. Results are referred to March, April and December

Table 6. Model Validation - Energy Audit B: natural gas consumption comparison

\begin{tabular}{|c|c|c|c|c|c|c|c|c|}
\hline \multirow{3}{*}{ Month } & \multicolumn{6}{|c|}{ Natural gas consumption } & \multicolumn{2}{|c|}{ Error } \\
\hline & \multicolumn{4}{|c|}{$\begin{array}{c}\text { Energy carrier bills } \\
{\left[\mathbf{m}^{3}\right]}\end{array}$} & \multicolumn{2}{|c|}{$\begin{array}{c}\text { Energy Audit B } \\
{\left[\mathrm{m}^{3}\right]}\end{array}$} & \multirow{2}{*}{$\begin{array}{c}\text { Absolute } \\
{\left[\mathrm{m}^{3}\right]}\end{array}$} & \multirow{2}{*}{$\begin{array}{c}\text { Relative } \\
{[\%]}\end{array}$} \\
\hline & total & $\mathbf{C}$ & $\mathbf{W}$ & $\mathbf{H}$ & $\mathbf{W}$ & $\mathbf{H}$ & & \\
\hline January & 37 & 1.5 & 5.8 & 29.7 & 5.8 & 33.7 & -4.1 & $-13.7 \%$ \\
\hline February & 26 & 1.5 & 5.8 & 18.7 & 5.8 & 15.9 & 2.8 & $14.7 \%$ \\
\hline March & 31 & 2.3 & 6.3 & 22.5 & 6.3 & 21.2 & 1.3 & $5.8 \%$ \\
\hline April & 24 & 2.9 & 7.0 & 14.1 & 7.0 & 13.9 & 0.2 & $1.2 \%$ \\
\hline May & 8 & 1.7 & 6.3 & 0.0 & 6.3 & 0.0 & - & - \\
\hline June & 6 & 1.3 & 4.7 & 0.0 & 4.7 & 0.0 & - & - \\
\hline July & 4 & 0.3 & 3.7 & 0.0 & 3.7 & 0.0 & - & - \\
\hline August & 3 & 0.2 & 2.8 & 0.0 & 2.8 & 0.0 & - & - \\
\hline September & 3 & 0.2 & 2.8 & 0.0 & 2.8 & 0.0 & - & - \\
\hline October & 4 & 0.5 & 3.5 & 0.0 & 3.5 & 0.0 & - & - \\
\hline November & 18 & 0.8 & 3.9 & 13.2 & 3.9 & 15.7 & -2.4 & $-18.4 \%$ \\
\hline December & 21 & 0.6 & 2.8 & 17.6 & 2.8 & 17.5 & 0.1 & $0.8 \%$ \\
\hline Total & 185 & 13.8 & 55.4 & 115.8 & 55.4 & 118.0 & -2.1 & $-1.6 \%$ \\
\hline
\end{tabular}




\subsection{Final remarks}

A comparison of two energy audits is needed. Results are summarized in Fig. 4 where the monthly natural gas consumption is shown. Results close to the billing are found, although on a yearly basis it can be stated that:

1) For energy audit A: a lower (of $2.6 \mathrm{~m}^{3}$ ) gas consumption for the heating is found;

2) For energy audit B: a higher (of $2.1 \mathrm{~m}^{3}$ ) gas consumption for the heating is found;

When March, April and December are considered as comparison period (i.e. the three months where all the information needed are provided by the user), the following outcomes can be drawn:

1) Energy audit A: a lower gas consumption of $1.9 \mathrm{~m}^{3}$ for the heating is found. The higher difference is simulated in March with an absolute error of $2.8 \mathrm{~m}^{3}$, while in the other two months a mean absolute error of $-0.4 \mathrm{~m}^{3}$ is highlighted;

2) Energy audit B: a lower gas consumption of $1.6 \mathrm{~m}^{3}$ for the heating is found. The higher difference is simulated in March with an absolute error of $1.3 \mathrm{~m}^{3}$, while in the other two months a mean absolute error of $+0.15 \mathrm{~m}^{3}$ is highlighted.

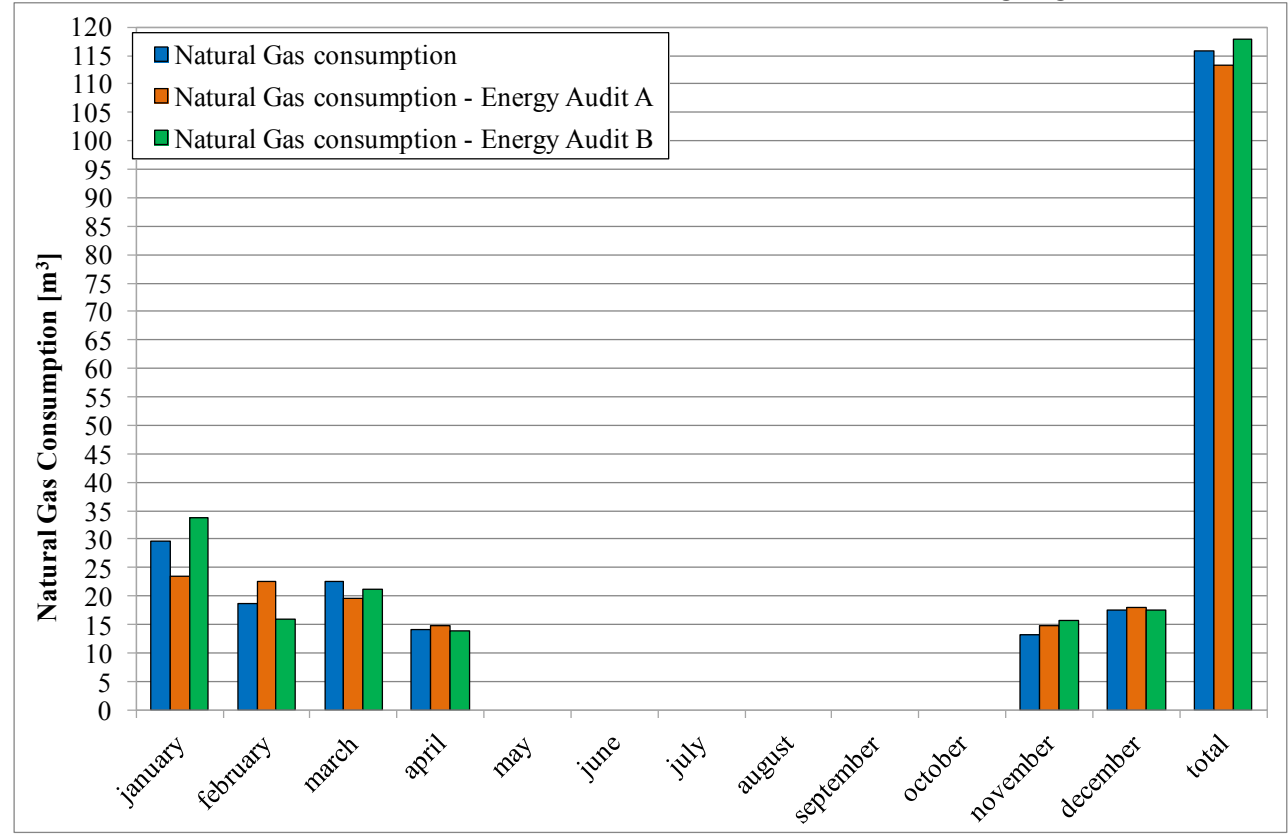

Fig. 4. Energy audit methodology comparison on gas consumption

\section{Conclusions}

In this work, the comparison amongst two ways to validate building energy audit derived from commercially available software simulation is carried out. The research gap to be filled is the finding of guidelines for energy audit models validation.

The first method (energy audit A) implies the use of billing data on gas consumption, the second method (energy audit B) entails a monitoring campaign of the indoor air temperature and air humidity, together with information on the occupancy schedule. 
The first method requires the knowledge of the billing and of other side information provided by the user (like for instance the number of meals and cocking time, number of showers, etc) to properly address the consumption to the other services that use natural gas.

The second method requires a monitoring campaign (the longer the lasting, the more reliable the results), and to retrieve from the temperature pattern the gas consumption for space heating. Therefore, in the latter case, the validation procedure is a bit more complex.

According to results, referred to a real building, it is worth noting that:

1) when data related to bills are available and when indoor environmental conditions are monitored (although for limited period), both methods allow to correctly simulate the real consumption for space heating with an acceptable absolute error;

2) when data related indoor environmental conditions are available for all the investigated period, the use of energy audit B is recommended because of its higher reliability, despite a more complex validation procedure.

It is reasonable to extend the conclusion to other high-efficiency envelope buildings: for this reason, other studies are ongoing.

\section{References}

1. F. Kalantzis, D. Revoltella. Energy Economics, 83, 229-239 (2019)

2. A. Kubule, K. Ločmelis, D. Blumberga. Energy, 202, 117679 (2020)

3. Directive 2012/27/EU of the European Parliament and of the Council of 25 October 2012 on energy efficiency, amending Directives 2009/125/EC and 2010/30/EU and repealing Directives 2004/8/EC and 2006/32/EC (2012)

4. UNI CEI EN 16247: Energy audits - Part 2: Buildings (2014)

5. UNI/TR 11775: Diagnosi Energetiche - Linee guida per le diagnosi energetiche degli edifici (2020), in Italian

6. A. O' Donovan, P.D. O' Sullivan, M.D. Murphy.Applied Energy, 240, 991-1010 (2019)

7. K.S. Cetina, M.H. Fathollahzadeh, N. Kunwar, H. Do, P.C. Tabares-Velasco. Energy Build, 183, 467-483 (2019)

8. C. Buratti, E. Belloni, D. Palladino. Energy Build, 74, 173-181 (2014)

9. T. de Rubeis, I. Nardi, M. Muttillo, D. Paoletti, J. Cult. Heritage, 43, 186-203 (2020)

10. UNI EN ISO 52016: Energy performance of buildings - Energy needs for heating and cooling, internal temperatures and sensible and latent heat loads - Part 1: Calculation procedures (2018) 